\title{
Desafios para a geoconservação em áreas vulneráveis: o exemplo da Bacia de Taubaté, Rifte Continental do Sudeste do Brasil
}

\author{
Challenges for geoconservation in vulnerable areas: the example of Taubaté Basin, \\ Continental Rift of Southeast Brazil
}

Reverte $^{1}$, F. C.; Garcia ${ }^{1}$, M. G. M.; Moura $^{2}$, T.T.

fernanda.reverte@usp.br;

\begin{abstract}
Resumo
A Bacia de Taubaté situa-se na porção leste do Estado de São Paulo e faz parte do segmento central do Rifte Continental do Sudeste do Brasil. Instalada durante o Eoceno/Oligoceno resulta de um campo de esforços distensivos de direção NW-SE, relacionado à reativação de zonas de cisalhamento cambrianas/ordovicianas no início do Paleógeno. Encontra-se numa área de grande atividade mineira que, associada ao caráter vulnerável de suas rochas e às ações antrópicas, contribui gradativamente com a perda de parte do patrimônio geológico local. Em virtude da rica geodiversidade associada ao seu contexto geológico, cinco categorias temáticas foram definidas, contribuindo com a etapa de inventário científico. Considerada uma "escola a céu aberto", a Bacia possui potenciais geossítios com interesses científico, didático, turístico e recreativo, que se encontram ameaçados de serem degradados de forma irreversível.
\end{abstract}

Palavras-chave: Bacia de Taubaté, Categorias temáticas, Geossítios Vulneráveis

\begin{abstract}
The Taubate Basin is located in the eastern portion of the State of São Paulo and is part of the central segment of the Continental Rift of Southeast Brazil. Installed during the Eocene/Oligocene, results from a field of extensional efforts of NW-SE direction, related to Cambrian/Ordovician shear zones at the beginning of the Paleogene. Located in an area of intense mining activity which, together with the vulnerable character of its rocks and antropic actions, gradually contributes to the loss of part of the local geological heritage. Due to the rich geodiversity associated with its geological context, five thematic categories were defined, contributing to the scientific inventory's stage. Considered an "open air school", the Taubaté Basin presents potential geosites with scientific, educational, tourist and recreation interests, which are threatened with being degraded in an irreversible way.
\end{abstract}

Keywords: Taubaté basin, Thematic categories, Vulnerable Geosites

\section{INTRODUÇÃO}

A geodiversidade existente no planeta decorre do conjunto de fenômenos e processos intrínsecos à dinâmica da Terra responsável pela origem de elementos como as rochas, minerais, fósseis e formas de relevo (Stanley, 2001). Estes recursos favoreceram o desenvolvimento da civilização ao disponibilizar alimentos, abrigo e materiais para construção, por exemplo, proporcionando plenas condições de subsistência e evolução de todas as espécies.

$\mathrm{O}$ aumento da procura por recursos naturais acarreta a produção de resíduos e emissão de poluentes que, sem o devido tratamento e destinação adequada, ameaçam cada vez mais a integridade da geodiversidade. Por se tratar de recursos naturais não renováveis em nossa escala de tempo geológico, a destruição desse patrimônio constitui uma perda irreparável, sendo necessário o

\footnotetext{
${ }^{\text {I} F e r n a n d a ~ C o y a d o ~ R e v e r t e ; ~ M a r i a ~ d a ~ G l o ́ r i a ~ M o t t a ~ G a r c i a ~-~ N u ́ c l e o ~ d e ~ A p o i o ~ a ̀ ~ P e s q u i s a ~ e m ~ P a t r i m o ̂ n i o ~ G e o l o ́ g i c o ~ e ~ G e o t u r i s m o ~}$ (GeoHereditas), Instituto de Geociências da Universidade de São Paulo, São Paulo - SP, Brasil

${ }^{2}$ Thaís Trevisani Moura - Programa de Pós-Graduação em Geoquímica e Geotectônica, Instituto de Geociências da Universidade de São Paulo, São Paulo-SP, Brasil
} 
desenvolvimento e atividades que visam à conservação e gestão sustentável do patrimônio geológico e dos processos naturais a ele associados, denominadas geoconservação (BRILHA, 2005).

O desenvolvimento de estratégias para a geoconservação de uma determinada região deve levar em consideração fatores como a relevância das informações geológicas observadas nos geossítios, além do grau de vulnerabilidade aos impactos a que estão submetidos, de modo a criar mecanismos que facilitem a aproximação das pessoas e também protejam estas áreas de interesse geológico.

A geodiversidade da Bacia de Taubaté contempla inúmeras formações que se constituem em excelentes locais para estudo, apresentando afloramentos com estratos ricos em fósseis, estruturas e feições que proporcionam pesquisa in situ caracterizando o grande potencial didático da área. A maioria destes afloramentos, no entanto, se encontra em condição vulnerável à destruição e degradação, tornando-se imprescindível preservá-los para que futuros estudantes possam visualizar de forma didática os processos que caracterizam uma bacia sedimentar e os registros da história geológica da região.

Localizada na porção leste do Estado de São Paulo, no médio curso do Rio Paraíba do Sul, a Bacia de Taubaté abrange os municípios de Jacareí, São José dos Campos, Caçapava, Taubaté, Tremembé, Pindamonhangaba, Roseira, Aparecida, Guaratinguetá, Lorena e Cruzeiro (Figura 1).

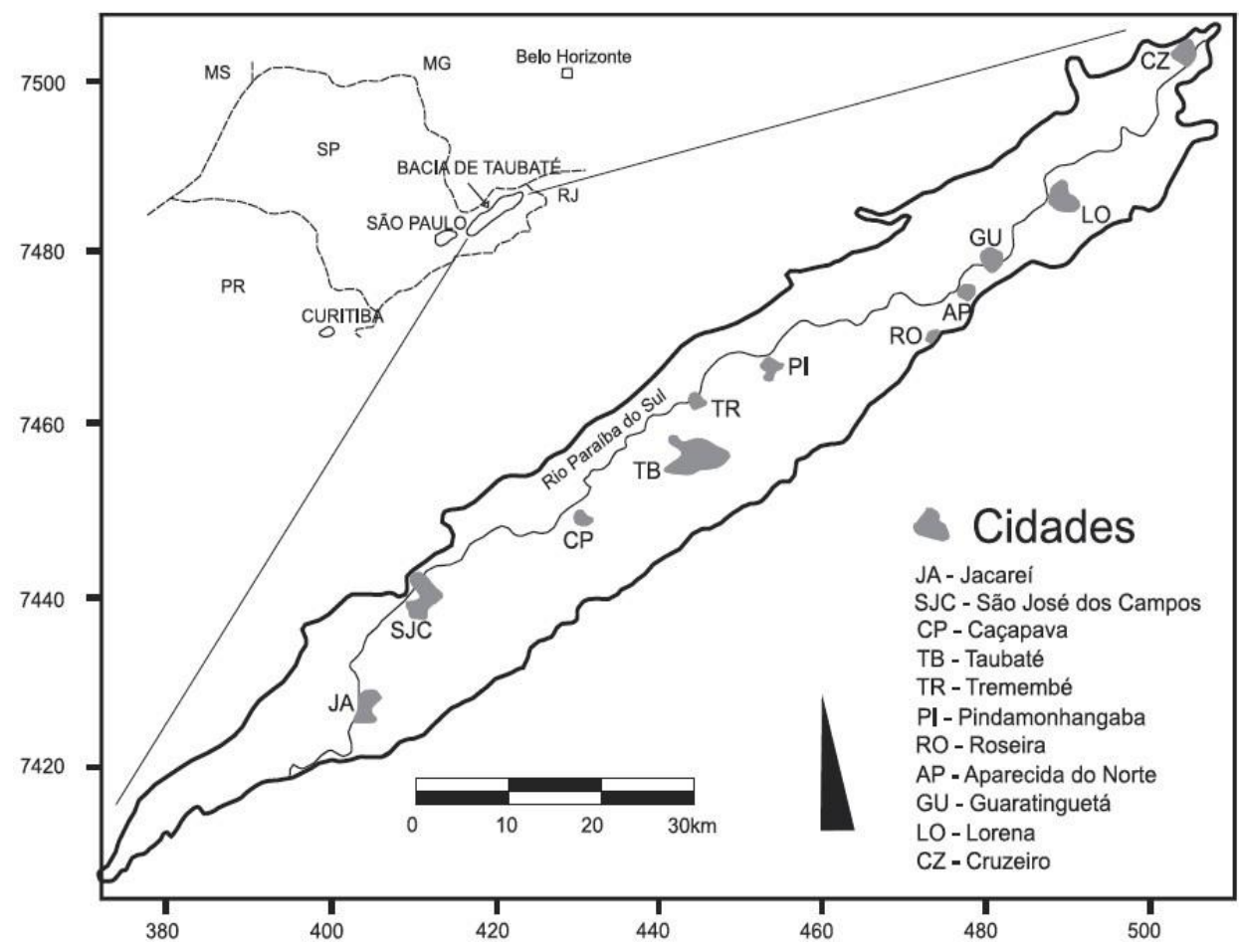

Figura 01. Mapa de localização da área de estudo com destaque para a localização da Bacia de Taubaté no Estado de São Paulo. Fonte: Carvalho et al.(2011) 
Geograficamente, se situa entre as serras do Mar e da Mantiqueira, no Planalto Atlântico, apresentando forma alongada com aproximadamente $170 \mathrm{~km}$ de comprimento e $25 \mathrm{~km}$ de largura, e profundidade sedimentar máxima de $850 \mathrm{~m}$ (Vidal et al., 2004). Trata-se de uma bacia sedimentar cenozoica, instalada sobre o embasamento pré-cambriano, tendo seu preenchimento sedimentar representado pelo Grupo Taubaté, além da Formação Pindamonhangaba e sedimentos quaternários (Freitas, 2007), cuja formação está associada à abertura do Oceano Atlântico. A região se destaca por constituir uma das mais importantes áreas para estudos paleontológicos do sudeste brasileiro, apresentando riqueza geológica que está se perdendo gradativamente em virtude da extrema vulnerabilidade de suas rochas constituintes, afetadas tanto pela ação antrópica, quanto pelo intemperismo.

Um dos fatores preocupantes à deterioração da geodiversidade local diz respeito à construção do Aerovale, o aeroporto do município de Caçapava, cujas obras foram embargadas pelo Ministério Público em março de 2015 devido aos danos ambientais gerados durante sua implantação. O empreendimento contará com lotes aeronáuticos, comerciais e industriais, os quais terão acesso direto à pista do aeroporto, além de terminal de cargas e passageiros. Embora seja um projeto de elevada relevância econômica para a região, a sua efetiva implantação poderá causar severos danos ao patrimônio geológico, ou até destruí-lo. Outro fator diz respeito à mineração de areias e de argilominerais esmectíticos, às margens do Rio Paraíba do Sul, que são utilizados na construção civil e por indústrias de fertilizantes há décadas e vêm exaurindo inúmeros afloramentos importantes da região (Figura 02). Além destes fatores, a própria ação do clima corrobora com a perda da geodiversidade local, visto que a região é constituída predominantemente por rochas sedimentares, que estão expostas a um grau de intemperismo maior.

Diante do exposto, para que ocorra a promoção da geodiversidade desta região, é necessário desenvolver ações que possam evitar que o patrimônio geológico, ou pelo menos parte dele, seja destruído. Estas ações podem emergir da concepção de um inventário científico, ao selecionar geossítios relevantes do ponto de vista geológico.

Por se tratar de uma área extensa, a metodologia tem início com a definição das categorias geológicas que irão direcionar o inventário e permitir a seleção de geossítios de valor científico a partir de contextos geológicos específicos. Desta forma, o presente trabalho tem como objetivo apresentar os métodos adotados no processo de inventário do patrimônio geológico da Bacia de Taubaté exemplificando os critérios de seleção utilizados na escolha dos frameworks em que se enquadram os geossítios locais. 


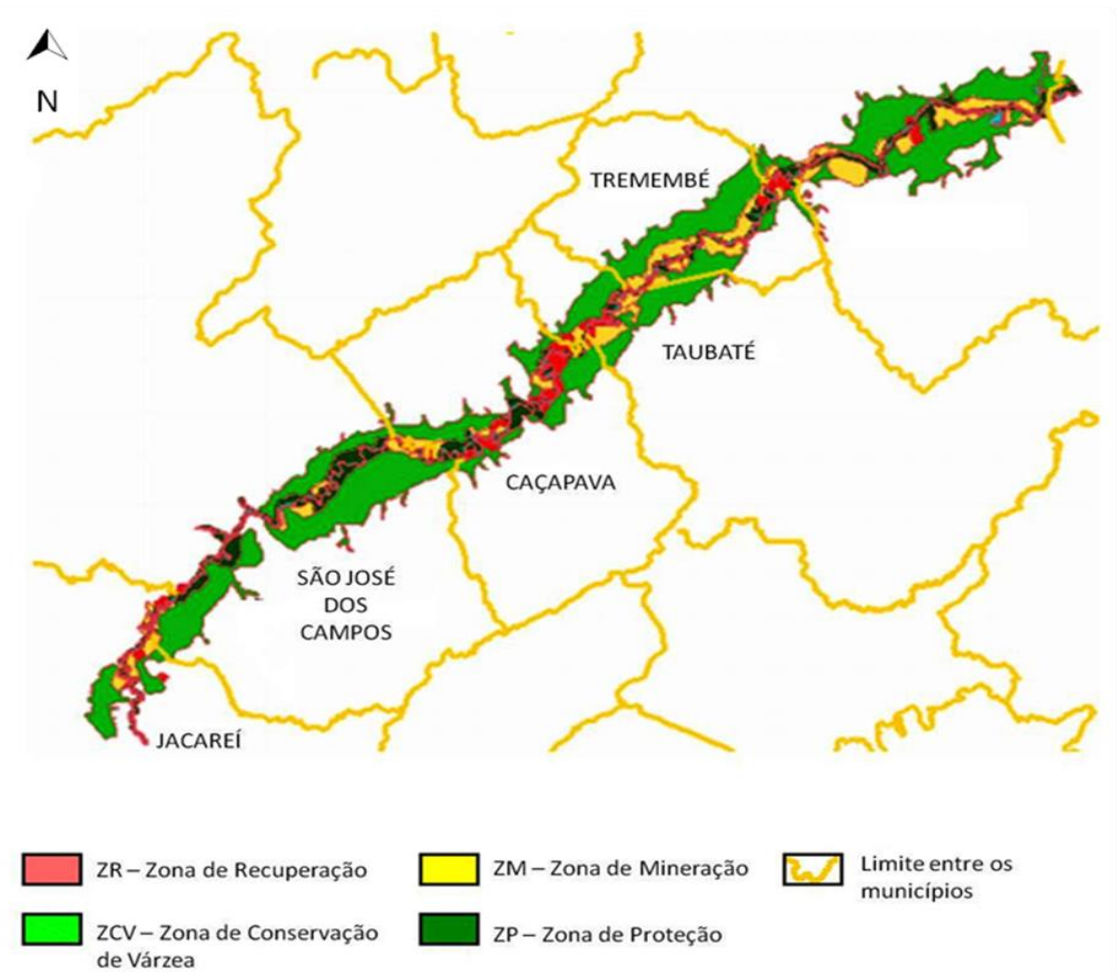

Figura 02. Zoneamento minerário da região da Bacia de Taubaté. Fonte: Simi et al.(2009)

\section{CONTEXTO GEOLÓGICO}

A Bacia de Taubaté faz parte de um conjunto de bacias pertencentes ao Rifte Continental do Sudeste do Brasil - RCSB - (Riccomini, 1989), tendo sido relacionada à fase tardia do evento de ativação tectônica da Plataforma Sul Americana, associada à fragmentação do supercontinente Gondwana e à formação do Atlântico Sul.

Posicionada no segmento central do RCSB, corresponde a uma bacia assimétrica formada internamente por regiões deprimidas e elevadas. Está relacionada à tectônica distensiva de idade paleógena e sua forma alongada está condicionada por descontinuidades antigas de direção geral ENE (Fernandes, 1993; Fernandes \& Chang, 2001; Riccomini et al., 2004). Assenta-se sobre rochas ígneas e metamórficas do Cinturão de Dobramentos Ribeira, datadas desde o Paleoproterozoico até o Neoproterozoico (Hasui \& Ponçano, 1978) e seu arcabouço é formado por semigrábens separados por zonas de transferências, com depocentros invertidos, em típica geometria de bacia do tipo rifte (Vidal et al., 2004). Estas zonas são representadas pelos altos de Caçapava e Pindamonhangaba e subdividiram a Bacia em três compartimentos: São José dos Campos, Taubaté e Aparecida (Figura 3). 
Apresenta uma sedimentação tipicamente continental e, segundo Riccomini (1989), o preenchimento pode ser dividido em duas fases: a primeira, sintectônica ao rifte, com a deposição dos sedimentos do Grupo Taubaté, composto pelas formações Resende, Tremembé e São Paulo, e a segunda, posterior à tectônica diastrófica, com a deposição da Formação Pindamonhangaba e depósitos aluviais e coluviais (Figura 4).

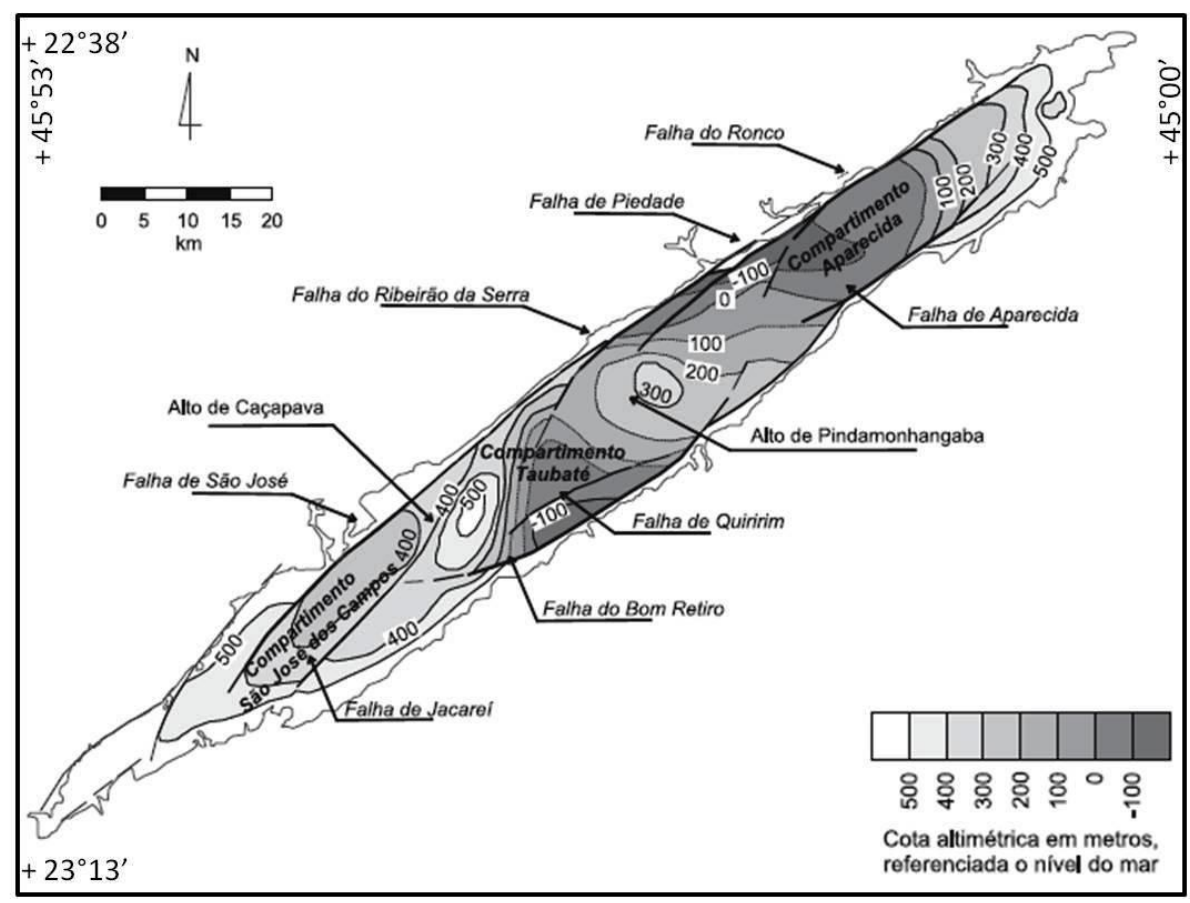

Figura 03. Mapa do arcabouço estrutural da Bacia de Taubaté. Fonte: Modificado Fernandes \& Chang (2001). 


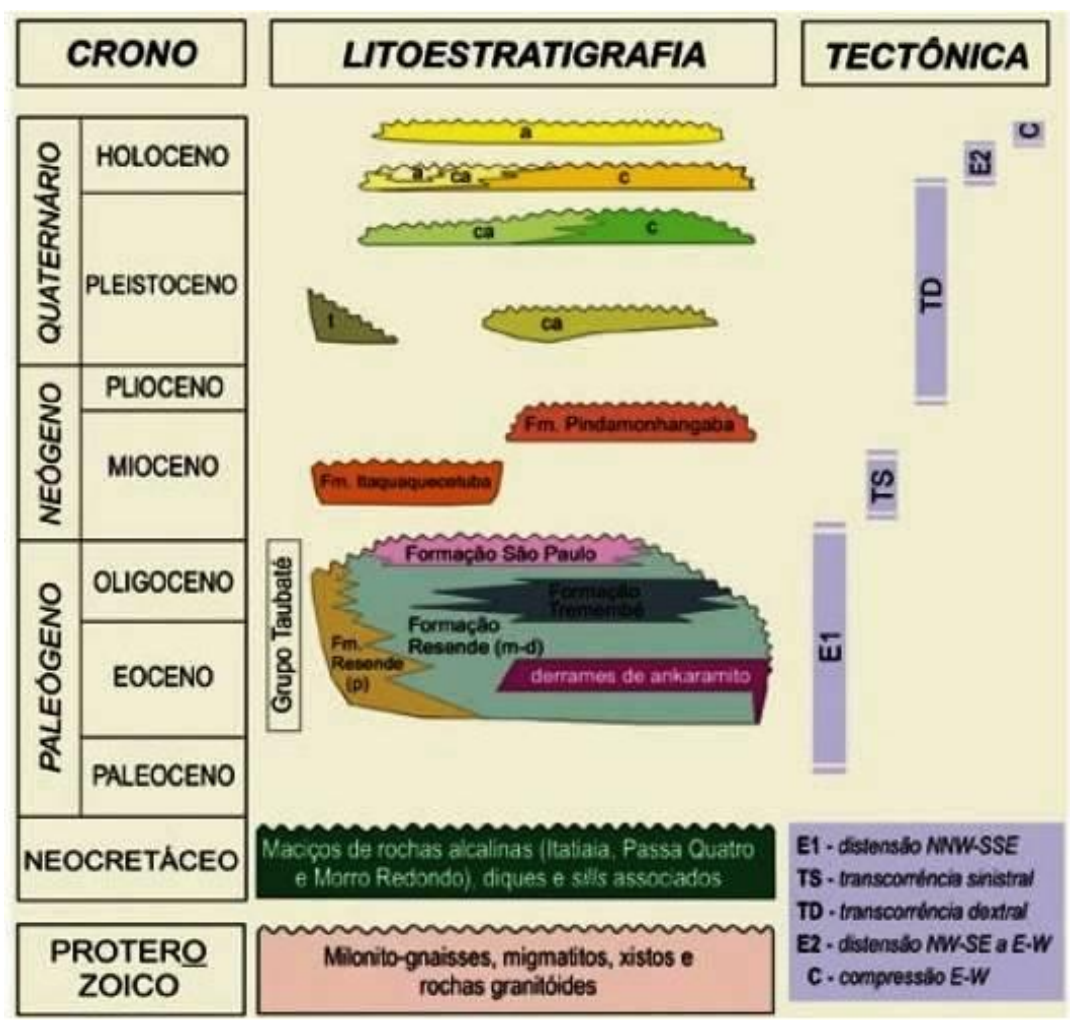

Figura 04. Litoestratigrafia e evolução tectono-sedimentar do RCSB. Fonte: Modificado de Riccomini (1989)

\section{METODOLOGIA}

A metodologia adotada para a pesquisa consiste primeiramente em realizar o inventário científico de potenciais geossítios da região por meio de pesquisa bibliográfica sobre a Bacia de Taubaté e consulta a pesquisadores. Para seleção preliminar de potenciais geossítios será adaptada a metodologia sugerida por Brilha $(2005,2015)$.

Segundo Lima (2008), o inventário do patrimônio geológico de uma dada região serve para suportar o desenvolvimento de outras ações relacionadas com a geoconservação, uma vez que compreende a identificação e caracterização dos geossítios, promovendo a sistematização do conhecimento geológico em uma base de dados. Corresponde, portanto, ao primeiro passo para se estabelecer estratégias de conservação de parte significativa da geodiversidade de determinado local, pois fundamenta ações de ordenamento territorial, divulgação do conhecimento geocientífico e geoturismo. Brilha (2015) ressalta que a ausência de um inventário da geodiversidade de uma dada região pode comprometer áreas de interesse científico, visto que muitos afloramentos que apresentam importantes evidências geológicas e tiveram décadas de estudos e pesquisas com gastos significativos podem desaparecer para sempre. Assim, os geocientistas devem assumir a responsabilidade social de garantir a conservação deste patrimônio natural de suma importância para o avanço das geociências e para o conhecimento do planeta Terra. 
Como meio de facilitar a elaboração do inventário, haja vista que a área de estudo é extensa, a metodologia se iniciou com a pesquisa bibliográfica para direcionar a definição das categorias temáticas que irão nortear a seleção de geossítios de valor científico de acordo com o contexto geológico da área. Tais categorias visam compreender os aspectos mais relevantes da geodiversidade local, de acordo com a história e evolução geológica e geomorfológica da região.

O presente trabalho é parte da pesquisa de doutorado da autora, intitulada "Proposta de metodologia para caracterização e plano de gestão de geossítios com alta vulnerabilidade: exemplo da Bacia de Taubaté, Rifte Continental do Sudeste do Brasil", e se encontra em fase inicial de desenvolvimento.

\section{RESULTADOS E DISCUSSÃO}

O Rifte Continental do Sudeste do Brasil (RCSB) compreende cerca de uma dezena de bacias, dentre as quais se destacam as de Curitiba, São Paulo, Taubaté, Resende, Volta Redonda, ltaboraí e Macacu, alojadas em uma depressão alongada segundo a direção geral ENE-WSW, perfazendo uma extensão de cerca de $1.000 \mathrm{~km}$ entre as cidades de Curitiba, no Paraná, e Barra de São João, no Rio de Janeiro. De idade cenozoica, o rifte segue grosseiramente a linha de costa atual, da qual dista em média cerca de $70 \mathrm{~km}$, alcançando o Oceano Atlântico em sua terminação nordeste.

O embasamento pré-cambriano da região é constituído por rochas metamórficas e ígneas, referíveis ao Ciclo Brasiliano. Ocorrem também intrusões de diabásio, comumente sob a forma de diques e soleiras, datados do Cretáceo Inferior (Amaral et al., 1966).

Os traços gerais da tectônica e estratigrafia da região do RCSB, compreendida entre as cidades de São Paulo e Volta Redonda, em uma extensão de cerca de $350 \mathrm{~km}$ de comprimento, foram descritos por diversos autores. Riccomini (1989), com base principalmente na análise cinemática de estruturas rúpteis e na análise de fácies sedimentares, amparado em dados mineralógicos, palinológicos, geocronológicos e geomorfológicos, entre outros, estabeleceu a seguinte sequência de seis eventos para a área estudada:

a) Paleógeno (Eoceno-Oligoceno): formação da depressão original (hemi-graben), contínua na porção analisada, como resultado do campo de esforços extensionais de direção NNW-SSE;

b) Neógeno: transcorrência sinistral de direção E-W, com extensão NW-SE e, localmente, compressão NE-SW;

c) Plioceno a Pleistoceno Inferior: implantação de novo sistema fluvial meandrante (Formação Pindamonhangaba) na porção central da Bacia de Taubaté, provavelmente em condições quente e úmida; 
d) Pleistoceno Superior: inicialmente fase de estabilidade tectônica com a deposição de sedimentos colúvio-aluviais;

e) Holoceno: nova extensão WNW-ESE (E-W), afetando depósitos de baixos terraços ligados à evolução da rede de drenagem do rio Paraíba do Sul; e

f) Atual: campo de tensões indicando compressão E-W, sugestivo de nova mudança no regime de esforços tectônicos.

Os fenômenos geológicos descritos representam a geodiversidade local, cujos registros encontram-se distribuídos em toda a região e contam a história geológica da Bacia de Taubaté.

Diante do exposto, com base em revisão bibliográfica e consulta a docentes e pesquisadores que atuam/atuaram na região, foram definidas cinco categorias temáticas (Tabela: 1) Abertura da bacia; 2) Deposição e Deformação Neógena; 3) Deposição e Deformação Quaternária; 4) Unidades geomorfológicas; e 5) Patrimônio paleontológico.

Até o momento, 28 potenciais geossítios foram catalogados por meio da metodologia descrita e dentre os elementos geológicos identificados, destacam-se os interesses: sedimentar, tectônico-estrutural, estratigráfico, geomorfológico, paleontológico e mineiro. Como a pesquisa está em andamento, outros pontos que surgirem serão estudados com o objetivo de selecionar os geossítios mais representativos para compor o inventário científico da Bacia de Taubaté.

Tabela 01. Distribuição dos geossítios dentro das categorias temáticas predefinidas

\begin{tabular}{l|l|l}
\hline Relação preliminar de geossítios da Bacia de Taubaté - Categorias Geológicas \\
\hline Categorias Temáticas & Breve descrição da categoria & $\begin{array}{l}\text { Quantidade de } \\
\text { geossítios }\end{array}$ \\
\hline Abertura da Bacia & $\begin{array}{l}\text { Embasamento pré-cambriano; } \\
\text { Formação da depressão (hemi-gráben); } \\
\text { Deposição do Grupo Taubaté. }\end{array}$ & 07 \\
\hline $\begin{array}{l}\text { Deposição e Deformação } \\
\text { Neógena }\end{array}$ & $\begin{array}{l}\text { Ocorrencia de esforços orientados para NW-SE e } \\
\text { compressão para NE-SE; } \\
\text { Deposição da Formação Pindamonhangaba. }\end{array}$ & 09 \\
\hline $\begin{array}{l}\text { Deposição e Deformação } \\
\text { Quaternária }\end{array}$ & $\begin{array}{l}\text { Nova extensão para NW-SE; } \\
\text { Deposição dos colúvios; } \\
\text { Compressão E-W. }\end{array}$ & 08 \\
\hline Unidades Geomorfológicas & $\begin{array}{l}\text { Mirantes com vista panorâmica para processos } \\
\text { associados à evolução da bacia e sedimentação. }\end{array}$ & 02 \\
\hline Patrimônio Paleontológico & Presença de fósseis. & 02 \\
\hline
\end{tabular}

\section{CONSIDERAÇÕES FINAIS}


O conhecimento adequado do patrimônio geológico de uma dada região fornece subsídios para a gestão sustentável e uso correto dos recursos hídricos, comportamento frente a fontes poluidoras, riscos geológicos, manutenção do meio ambiente, promoção do geoturismo, dentre outros, apontando as adequabilidades e limitações para o uso e ocupação dos terrenos.

A Bacia de Taubaté é considerada por muitos professores uma "escola a céu aberto", pois possui diversos afloramentos que apresentam elevado interesse científico e didático e são frequentemente utilizados em trabalhos de campo, principalmente por estudantes de ciências da Terra, a exemplo do geossítio denominado "Tabuões". Por esse motivo, é essencial que os geossítios sejam preservados para que futuros estudantes possam visualizar de forma didática os processos, registros e estruturas que caracterizam uma bacia sedimentar.

A metodologia adotada permitiu a definição das categorias temáticas, otimizando a seleção dos geossítios ao classificá-los em um contexto geológico pertinente à sua história, favorecendo a compreensão da evolução tectônica local. Como a pesquisa está em andamento, tanto os geossítios apresentados, quanto as categorias temáticas, poderão sofrer modificações.

O caráter extremamente vulnerável das exposições de rochas e estruturas na região da bacia constitui-se num desafio à gestão do patrimônio geológico. Informações obtidas por meio da identificação e do monitoramento das principais ameaças serão utilizadas na proposição de uma metodologia específica, voltada diretamente a geossítios vulneráveis. Espera-se, com isso, contribuir com a manutenção de um ecossistema sustentável e com a preservação do patrimônio geológico para usufruto das futuras gerações.

\section{REFERÊNCIAS}

AMARAL, G.; BUSHEE J; CORDANI, U.G, KAWASHITA K.; REYNOLDS, J.H. Potassiumargon ages of basaltic rocks from southern Brazil. Geochimica et Cosmochimica Acta, 30: 154180. 1966.

BRILHA, J. B. R. Inventory and Quantitative Assessment of Geosites and Geodiversity Sites: a Review. Geoheritage, v. 1, p. 1. 2015.

BRILHA, J. B. R. Patrimônio Geológico e Geoconservação: a conservação da natureza na sua vertente geológica. Palimage Editora, 2005. 190 p.

CARVALHO, A.M.A., VIDAL, A.C., CHANG, H.K. Delimitação do embasamento da Bacia de Taubaté. Revista do Instituto de Geociências - USP, v. 11, n.1, p. 19-32. 2011. 
FERNANDES, F.L. \& CHANG, H.K. Modelagem gravimétrica da Bacia de Taubaté - Vale do Rio Paraíba do Sul, leste do Estado de São Paulo. Revista Brasileira de Geofísica, 2001. 19:131-144. FERNANDES, F.L. Arcabouço estrutural e evolução da Bacia de Taubaté - SP. Dissertação de Mestrado, Universidade Federal de Ouro Preto, Ouro Preto, MG. 1993. 147 p.

FREITAS, M. S. Estratigrafia de Alta Resolução e Geoquímica Orgânica da Formação Tremembé, Terciário da Bacia de Taubaté, na região de Taubaté-Tremembé-SP. Programa de Pós-graduação em Análise de Bacias e Faixas Móveis, Universidade do Estado do Rio de Janeiro, 2007. 98 p.

HASUI, Y. \& PONÇANO, W.L. Organização estrutural e evolução na Bacia de Taubaté. In: Congresso Brasileiro e Geologia, v. 1, Anais... Recife, Pernambuco, 1978. 368-381 p.

LIMA, F. F. Proposta metodológica para a inventariação do Patrimônio Geológico Brasileiro. Dissertação de Mestrado em Patrimônio Geológico e Geoconservação Escola de Ciências, Universidade do Minho, Portugal, 2008, 90 p.

RICCOMINI, C. O rift continental do sudeste do Brasil. São Paulo. Dissertação de Doutorado, Instituto de Geociências, Universidade de São Paulo, São Paulo, 1989. 256 p.

RICCOMINI, C., SANT’ANNA, L. G., FERRARI, A. L. Evolução geológica do rift continental do sudeste do Brasil. In: Mantesso-Neto, V., Bartorelli, A., Carneiro, C.D.R., et al. (eds). Geologia do continente SulAmericano: evolução da obra de Fernando Flávio Marques de Almeida, 1 ed., São Paulo, Beca Produções Culturais Ltda, 2004. cap. 23.

SIMI, R.; SIMI JUNIOR, R.; RUDORFF, B F T. Monitoramento e Análise da Evolução das Cavas de Areia na Várzea do Rio Paraíba do Sul. In: XIV Simpósio Brasileiro de Sensoriamento Remoto, 2009, Natal. Anais XIV Simpósio Brasileiro de Sensoriamento Remoto. São José dos Campos: INPE, 2009. p. 5467-5474

STANLEY, M. 2001. Geodiversity Strategy. ProGeo News, n.1, 2001. p.6-9.

VIDAL, A. C., FERNANDES, F. L. \& CHANG, H. K. Distribuição dos arenitos da Bacia de Taubaté - SP. Geociências - UNESP. n. 1/2, v. 23, p. 55-66. 2004

Recebido em: 14/08/2016

Aceito para publicação em: 01/10/2016 